\title{
Is a little sunshine all we need? On the impact of sunshine regulation on profits, productivity and prices in the Dutch drinking water sector
}

\author{
Kristof De Witte · David S. Saal
}

Published online: 12 December 2009

(C) The Author(s) 2009. This article is published with open access at Springerlink.com

\begin{abstract}
This paper analyzes the performance of Dutch drinking water utilities before and after the introduction of sunshine regulation, which involves publication of the performance of utilities but no formal price regulation. By decomposing profit change into its economic drivers, our results suggest that, in the Dutch political and institutional context, sunshine regulation was effective in improving the productivity of publicly organised services. Nevertheless, while sunshine regulation did bring about a moderate reduction in water prices, sustained and substantial economic profits suggest that it may not have the potential to fully align output prices with economic costs in the long run. In methodological terms, the DEA based profit decomposition is extended to robust and conditional non-parametric efficiency measures, so as to account better for both uncertainty and differences in operating environment between utilities.
\end{abstract}

Keywords Regulation · Drinking water utilities · Profit decomposition · Data Envelopment Analysis

JEL Classification $\quad \mathrm{C} 14 \cdot \mathrm{L} 33 \cdot \mathrm{L} 51 \cdot \mathrm{L} 95$

\footnotetext{
K. De Witte $(\varangle)$

Center for Economic Studies, Katholieke Universiteit Leuven (KUL), Naamsestraat 69, 3000 Leuven, Belgium

e-mail: kristof.dewitte@econ.kuleuven.be

K. De Witte

Top Institute for Evidence Based Education Research, Maastricht University, Tongersestraat 55, 6200 MD Maastricht, The Netherlands

D. S. Saal

Economics and Strategy Group, Aston Business School, Aston University, Birmingham, B4 7ET, UK e-mail: d.s.saal@aston.ac.uk
} 


\section{Introduction}

The regulation of public and private utilities changed significantly over the last several decades as new ideas and paradigms were developed and dismissed (Crew and Kleindorfer 2002). However, privatization and/or regulation with an appropriate form of incentive regulation are widely considered to be appropriate policy responses, as for example demonstrated by the privatization and subsequent regulation of water utilities in England and Wales, and the establishment of incentive regulation regimes, despite the retention of public ownership, for many Australian water utilities. For a particular sector, the transition from one regulatory model to another also involves heated debates, which can create instability in the regulated sector that in turn influences economic profits, investments, firm performance and prices (Parker 1999).

In this paper, we consider the case of the publicly owned Dutch drinking water sector, which experienced several regulatory initiatives over the period between 1992 and 2006. However, this regulatory reform process ultimately resulted in the retention of public ownership and the implementation of a light-handed sunshine regulation regime in 1997. In the Dutch water sector, sunshine regulation corresponds to an application of benchmarking (i.e., a comparison of utilities) in which the outcome of the benchmarking exercise is made publicly available so as to embarrass the least performing entities and to put the best performing entities into the limelight (in contrast to yardstick competition which uses the benchmark results to set maximum prices or revenues). The Dutch drinking water sector therefore provides an interesting example where privatisation and the establishment of a mandatory incentive regulation regime were considered, but ultimately rejected in favour of an alternative approach.

The debate on reforming the Dutch drinking water utilities is also part of a broader debate among both academics and practitioners (Bauer 2005). The literature focuses especially on the privatization issue, regulatory problems (e.g., Ugaz and Price 2003) or institutional structures (e.g., Spiller and Tommasi 2004). Although connected to this branch of the literature, the focus of the current analysis is on the performance effects arising from a system that relies on the voluntary publication of performance indicators, while imposing no formal regulatory link between relative performance and prices.

We therefore analyze performance change using an input-oriented non-parametric profit decomposition variant of the approach developed by Grifell-Tatjé and Lovell (1999, 2008). This approach allows us to decompose changes in economic profits, and thereby identify the relationship between the economic opportunity cost of producing water services and the revenues raised by water utilities. While our profit decomposition analysis largely follows the lead of Grifell-Tatjé and Lovell (1999), we nonetheless substantially extend their underlying Data Envelopment Analysis (DEA) efficiency model to a more advanced input-oriented non-parametric model, and therefore highlight the following three extensions that should improve the reliability of the underlying efficiency estimates. Firstly, by implementing robust order- $m$ efficiency estimates (Cazals et al. 2002) we employ a DEA model which should reduce the influence of atypical observations. The latter could arise from (1) measurement errors, (2) the various mergers in the sector or (3) wrongly estimated values due to the use of data that adheres to accounting rules (e.g., Taylor 1999; Salvary 2003). Secondly, 
we employ Daraio and Simar (2007) approach to further extend the robust order- $m$ model to incorporate heterogeneity in the efficiency analysis. We thereby account for the exogenous environment of the drinking water utilities by controlling for population density, which is widely considered to be an important determinant of water utility input requirements (see Filippini et al. 2008). We therefore obtain more reliable profit decomposition results than would be obtained if we ignored such differences in operating environment. Thirdly, by using a window analysis technique, we allow for the possibility of both technical regress and progress in the model, thereby allowing better estimation of efficient input requirements in any given year.

As our below results demonstrate, our adaptation of Grifell-Tatjé and Lovell's approach allows a detailed analysis of how factors such as (1) output and input prices, (2) productivity, and (3) changes in the structure of firms, such as, their resource mix and scale have influenced profitability in the sector, and how consumers have, or have not benefited from these changes. Moreover, our analysis demonstrates that substantial performance improvements appear to have been obtained from the introduction of sunshine regulation for Dutch drinking water utilities, and despite the ultimate rejection of privatization and strict incentive regulation regime with binding price caps.

The paper unfolds as follows. In the next section, we briefly review developments in the Dutch drinking water sector over the past two decades. Section 3 presents the input-oriented profit decomposition model while Sect. 4 outlines the methodology for estimating the unobserved quantities which are required for the profit decomposition. Section 5 discusses the particular application and its results. In the final section we offer our conclusions.

\section{The development of the Dutch drinking water sector}

Since the early 1990s, the Dutch drinking water sector has experienced an extended period of debate with regard to its structure and regulatory model. In the 1992-2006 period, there were various debates between advocates and opponents of privatization and strict regulation. However, ultimately the sector has remained in public ownership and has been regulated since 1997 with a relatively light-handed sunshine regulation system. While this system has resulted in the publication of benchmarking reports based on 1997, 2000, 2003, and 2006 data, these benchmarking exercises do not result in the implementation of formal price regulation. Our below analysis will therefore consider the sources of profit change in the pre sunshine period 1992-1997, the entire post sunshine period 1997-2006, and the sub periods 1997-2000, 2000-2003, and 2003-2006 as defined by the years in which public benchmarking was performed. By analyzing several sector publications (mainly Waterspiegel published by the Association of Dutch Water Companies (Vewin), the annual accounts of the utilities and opinion articles in the Dutch financial press), we can briefly describe developments in the Dutch drinking water sector during these periods. However, we also note that after the introduction of sunshine regulation in 1997, regulatory policy and industry trends are more consistent, with only relatively minor variation between the sub periods. This section does not intend to exhaustively describe the history of the Dutch drinking 
water sector (see Kuks 2006; Van Dijk et al. 2007), but rather it summarizes changes in and debates about its structure and regulatory model.

\subsection{The pre sunshine period: $1992-1997$}

By the beginning of the 1990s the Dutch government implemented privatization and liberalization in several network sectors (e.g., the telecommunication and energy sectors). However, the water industry remained an unreformed public sector utility, where for example prices were insufficient to cover economic costs. Thus, in 1992, by our calculations (details are provided below in Sect. 5), the companies made aggregate real (in 1995 prices) economic losses of 97.6 million euros, as revenues were not sufficient to cover economic costs. However, given the anticipated privatization of the water sector, efforts were made to improve the financial strength of the drinking water utilities by increasing consumer prices. As a result, by 1995 the industry became economically profitable and by 1997 it had achieved profits of 139.5 million euros. However, while this increase in consumer prices restored the financial viability of the utilities, by 1997, a government report stated a clear relationship between the monopolistic provision of drinking water and its high costs and prices. The report's authors argued that the introduction of incentive regulation would reduce water prices by at least $7 \%$ (Dijkgraaf et al. 1997). However, despite this analysis, as well as the sector's financial preparation for privatisation, there was in fact insufficient political support in the mid 1990s for the government to be able to actually implement privatisation and/or an incentive regulation system. Given this political reality, policy makers sought a policy response that would allow for efficiency improvements while retaining public ownership, in at least the interim before future potential privatisation.

\subsection{The post sunshine period: 1997-2006}

\subsubsection{The period 1997-2000}

The Dutch drinking water sector organization Vewin was strongly opposed to any idea of strict incentive regulation. However, thanks to political pressures to increase transparency and efficiency in the sector and in order to avoid privatization which might become necessary without efficiency improvements (following the English and Welsh utilities), in 1997 Vewin started a voluntary benchmarking scheme which was used for sunshine regulation (Waterspiegel 2001).

The effectiveness of Dutch sunshine regulation depends on both internal and external carrots and sticks. Internal incentives arrive from increased transparency, the diffusion of best practices by sector-specific workshops, improved knowledge of priorities in the company and financial rewards for managers if they are able to improve the utility's position in the sunshine ranking. The drinking water utilities' annual accounts also explicitly set targets detailing their desired performance (e.g., a place in the top-three on all benchmarked issues). External incentives are driven by public interest in the water sector as the media heavily report the sunshine results. In addition, the water companies are owned by the provincial and municipal governments which in 
turn are elected by the citizens in the service area of the utility. As is common practice in the Netherlands, in the remainder of the text we will use the terms of 'sunshine regulation' and 'benchmarking' as equivalents.

The Vewin benchmark is implemented in a three year cycle. In the first two years only costs are compared, and these results are only internally published among the drinking water utilities. However, in the third year an external 'benchmark' is generated which provides figures and rankings on factors such as quality, service, environmental issues and costs. The first public benchmark considered 1997 data and was published in March 1999. The second public benchmark analysed 2000 data and was published in November 2001. The third issue uses 2003 data, and was published in November 2004, while the latest version employs 2006 data and was published in September 2007.

Several academic studies have considered the development of cost efficiency in the Dutch drinking water sector and suggest that the sunshine regulatory system has led to improvements in the cost performance of the sector (Kuks 2006; Dijkgraaf et al. 2007a; De Witte and Dijkgraaf 2008). Thus, while water quality and service levels steadily increased, the sector also experienced a considerable increase in cost efficiency of $23 \%$ between 1997 and 2006. Increased transparency and political pressures to gain scale economies by creating a single drinking water company in each province also led to intensified merger activity from 1996 onwards, and as a result, the number of drinking water companies halved between 1992 and 2007. However, while potential scale economy benefits have been the justification for these mergers, recent empirical work finds no evidence to support the accrual of scale economy benefits from these mergers (De Witte and Dijkgraaf 2008). Conversely, by decreasing the number of reference observations in the benchmark, the mergers may have reduced the potential effectiveness of benchmarking in identifying underperformance. Our below analysis will also shed further light on the benefits gained through improved efficiency and scale changes, while also integrating these effects into a more robust analysis of the determinants of the sector's overall productivity and profit performance.

\subsubsection{The period 2000-2003}

After the publication of the first two benchmarking reports, a policy debate with regard to the ownership of the water utilities began once again in the Dutch parliament. However, in 2003, after two years of discussions, the continued lack of sufficient political support for privatisation, and prompted by positive results from the sunshine regulation regime, the Dutch parliament reserved the drinking water sector as a public domain, which implied a moratorium on private investments. The Dutch drinking water utilities therefore continue to be structured as Public Limited Companies (PLCs) in which the provinces and municipalities own the assets. It is notable that the provinces are also responsible for regulating drinking water tariffs and, therefore, potential conflicts in interest may arise. For all utilities but one, the shareholders' meeting can decide on the payment of a dividend to the shareholders (i.e., the provinces and municipalities). Some utilities decided not to return a dividend, whereas other opted for one percent point above the 10-year guild bond, still others return up to $57 \%$ of the profits to the shareholders (for an overview on all utilities, see Dijkgraaf et al. 2007b). 
In addition to discussing the ownership of the water utilities, during this period the government also proposed a new law which would have applied a formal system of yardstick competition to the sector. However, the idea of establishing yardstick competition was finally buried in early 2004 when a new Minister took office.

\subsubsection{The period 2003-2006}

In this period critical articles began to appear in the press emphasizing 'excessive' profits, and as a result, public awareness and concerns regarding profits in the water sector increased. Our below analysis of economic profitability, demonstrates the cause of this increased concern as in our sample of firms real (in 1995 prices) aggregate economic profits increased from 146.6 million euros in 2002 to 241.3 million euros in 2005. As a response, the sector stressed that until 2000 drinking water prices increased more than the consumer price index (CPI), but from 2000 onwards drinking water prices increased less than CPI. However, given that economic profits in the industry remain very high relative to their level in the early 1990s, it is clear that these below inflation increases in water prices have not substantially eroded the high levels of economic profitability achieved in the sector. Moreover, as provincial governments are the ultimate beneficiaries of these high economic profits, it would appear that water tariffs are now set above economic costs, which implies that water consumers implicitly subsidize other government activities. This is in stark contrast to the situation in 1992, when the presence of economic losses suggests that Dutch water consumers did not pay the full economic cost of their water usage.

In sum, our review suggests that the Dutch drinking water sector provides a somewhat unusual example that warrants careful analysis. This is the case, because the industry has undergone substantial mergers and adopted a new regulatory regime, despite the fact that it has not been privatized. Moreover, it has dramatically increased its profitability, which previous papers and general policy debate suggest may be attributable to improved efficiency/productivity and/or substantial increases in water prices for consumers. Given this, it is interesting to look behind the profit change by decomposing it into its underlying drivers. Moreover, by linking changes in profitability and its drivers to regulatory and structural changes that have occurred over the 1992-2006 period, we can better understand the drivers of performance in the Dutch drinking water industry, and contribute to the current policy debate with regard to the appropriateness of regulation and prices in the Dutch water industry. The two proceeding sections therefore develop a non-parametric model that will allow us to do this.

\section{Decomposing profit change}

Consider $n$ utilities which are using $p$ heterogeneous and non-negative inputs $x$ $\left(x_{1}, \ldots, x_{p}\right)$ to produce $q$ heterogeneous and non-negative outputs $y\left(y_{1}, \ldots, y_{q}\right)$. The utilities buy inputs at input prices $w\left(w_{1}, \ldots, w_{p}\right)$ and sell outputs at output prices $p\left(p_{1}, \ldots, p_{q}\right)$, which could be either exogenously or endogenously 
determined. Economic profits $\pi^{t}$ in time period $t(t=1, \ldots, T)$ are determined as total revenues minus total economic costs:

$$
\pi^{t}=\sum_{m=1}^{q} p_{m}^{t} y_{m}^{t}-\sum_{l=1}^{p} w_{l}^{t} x_{l}^{t}
$$

where in the remainder of the article we will drop the subscripts and consider the variables as vectors. In their interesting contributions, Grifell-Tatjé and Lovell (1999, 2008) look at the change in economic profits between two time periods and decompose this profit change into its drivers. In this section, we present the complementary input-oriented analytical model to the original output-oriented decomposition of Grifell-Tatjé and Lovell (1999). ${ }^{1}$ Firstly, consider the decomposition of the profit change between period $t+1$ and period $t$ into a quantity and a price effect:

$$
\begin{aligned}
\pi^{t+1}-\pi^{t}=[ & \left.\left(y^{t+1}-y^{t}\right) p^{t}-\left(x^{t+1}-x^{t}\right) w^{t}\right] \\
& +\left[\left(p^{t+1}-p^{t}\right) y^{t+1}-\left(w^{t+1}-w^{t}\right) x^{t+1}\right] .
\end{aligned}
$$

The quantity effect (i.e., the first term in squared brackets) measures for constant base period prices the impact on profit change arising from the change in outputs relative to the change in inputs. As such, it measures the performance of the evaluated entity, while eliminating input and output price fluctuations. The price effect (i.e., the second term in squared brackets) estimates, for a fixed reference basket, the impact of input and output price fluctuations on profit change between period $t$ and $t+1$.

We enrich the profit decomposition by allowing for relative inefficiencies (i.e., relative to the set of best practice observations; see Grifell-Tatjé and Lovell 1999). Analyzing inefficiencies requires an assumption on the efficiency measurement orientation. We will focus on the input-orientation (i.e., minimizing input usage for a given set of outputs) as this is the most natural in our empirical application. Thus, we assume that drinking water utilities should try to reduce their input usage given their level of drinking water production. Allowing for inefficiencies, profit change can now be driven by increases in productivity or by improvements in the activity mix (all expressed in base period prices). This can be seen by further decomposing the quantity effect as follows:

$$
\begin{aligned}
& \left(y^{t+1}-y^{t}\right) p^{t}-\left(x^{t+1}-x^{t}\right) w^{t}=\left[\left(x^{t}-x^{A}\right) w^{t}-\left(x^{t+1}-x^{C}\right) w^{t}\right. \\
& \left.+\left(x^{A}-x^{B}\right) w^{t}\right]+\left[\left(y^{t+1}-y^{t}\right) p^{t}-\left(x^{C}-x^{B}\right) w^{t}\right] .
\end{aligned}
$$

The first term in squared brackets is referred to as the productivity effect, but can be further decomposed as the sum of the impact on profit change resulting from (1) the evaluated entity's efficiency improvement relative to the best practice frontier (i.e., the difference between the first two terms) and (2) technical progress (if

\footnotetext{
1 The recent contribution of Grifell-Tatjé and Lovell (2008) discusses a particular variant of the input-oriented framework.
} 


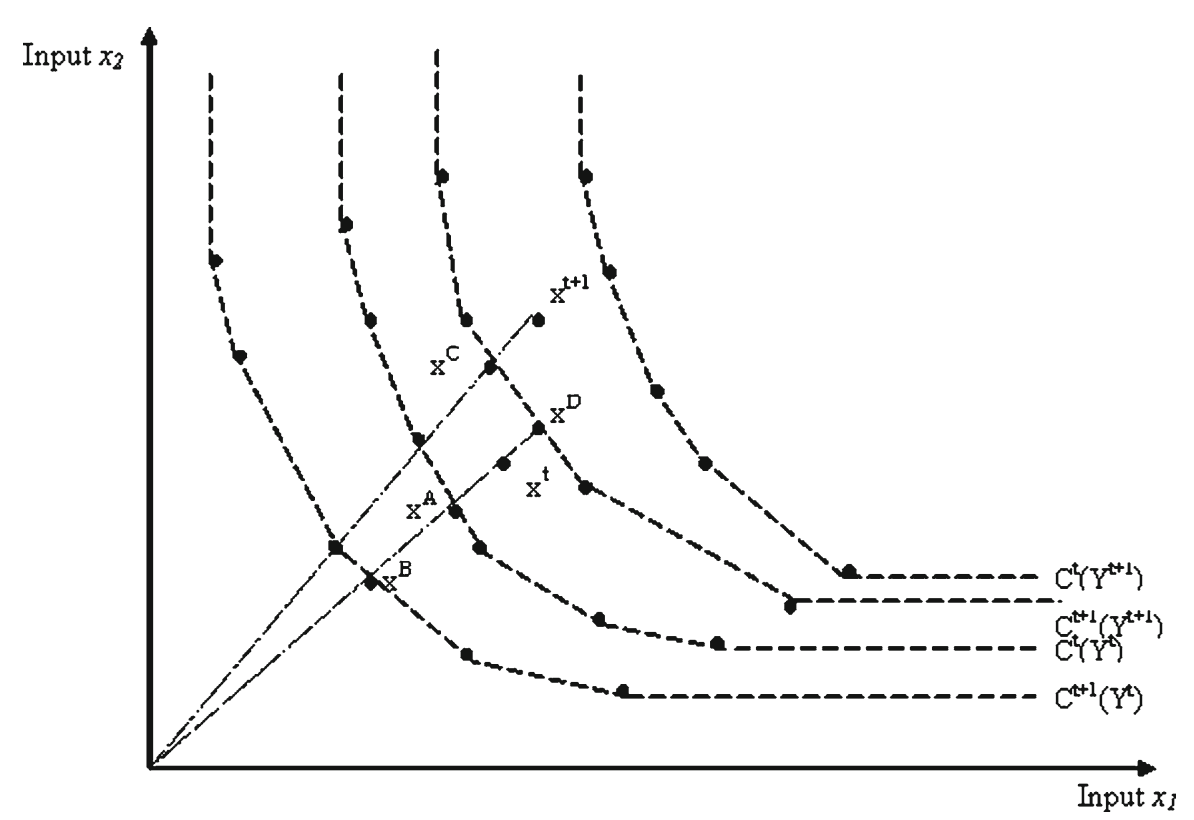

Fig. 1 Input efficient boundaries

$x^{A}-x^{B}>0$ ) or technical regress (if $x^{A}-x^{B}<0$ ) between period $t$ and $t+1$. The former component is denoted as the efficiency change (or catch-up effect), while the latter component is labeled as technical change. An increase in efficiency has a positive influence on profit change, as does technical progress. Grifell-Tatjé and Lovell (1999) argue that the input-oriented efficiency scores $(\theta)$ of a non-parametric model, which measure excessive input use for a given output set without assuming an a priori specification on the production function, can be used to deduce the unobserved inputs $x^{A}, x^{B}$ and $x^{C}$ as, respectively, $\theta^{t}\left(x^{t}, y^{t}\right) * x^{t}, \theta^{t+1}\left(x^{t}, y^{t}\right) * x^{t}$ and $\theta^{t+1}\left(x^{t+1}, y^{t+1}\right) * x^{t+1}$ (i.e., the radial projection of $x^{t}$ and $x^{t+1}$ on to the respective frontier). While the practical computation of $\theta$ is explored in the next section, Fig. 1 illustrates the relationship between $x^{A}, x^{B}, x^{C}, x^{t}$ and $x^{t+1}$ for a two-dimensional input vector.

The second term in squared brackets is the activity effect, which captures the impact on profit change arising from shifts in the firm's activities, as measured by changes in output and input levels evaluated using constant base period prices. Decomposing the activity effect further reveals that its components capture the impact on profitability of changes in scale and scope between period $t$ and $t+1$.

To illustrate this decomposition of the activity effect consider again Fig. 1, as well as Fig. 2. In Fig. 1, the efficient input boundary $C^{t+1}\left(y^{t}\right)$ indicates the minimum input requirements to produce a given output level $y^{t}$ using the best practice technology available in $t+1$. To produce efficiently the base period output level $y^{t}$ in the reference period $t+1, x^{B}$ inputs are needed. Subsequently increasing the outputs to $y^{t+1}$, but holding the input mix constant, requires $x^{D}$ inputs. The difference between $x^{B}$ and $x^{D}$ therefore reflects the input scale effect. 


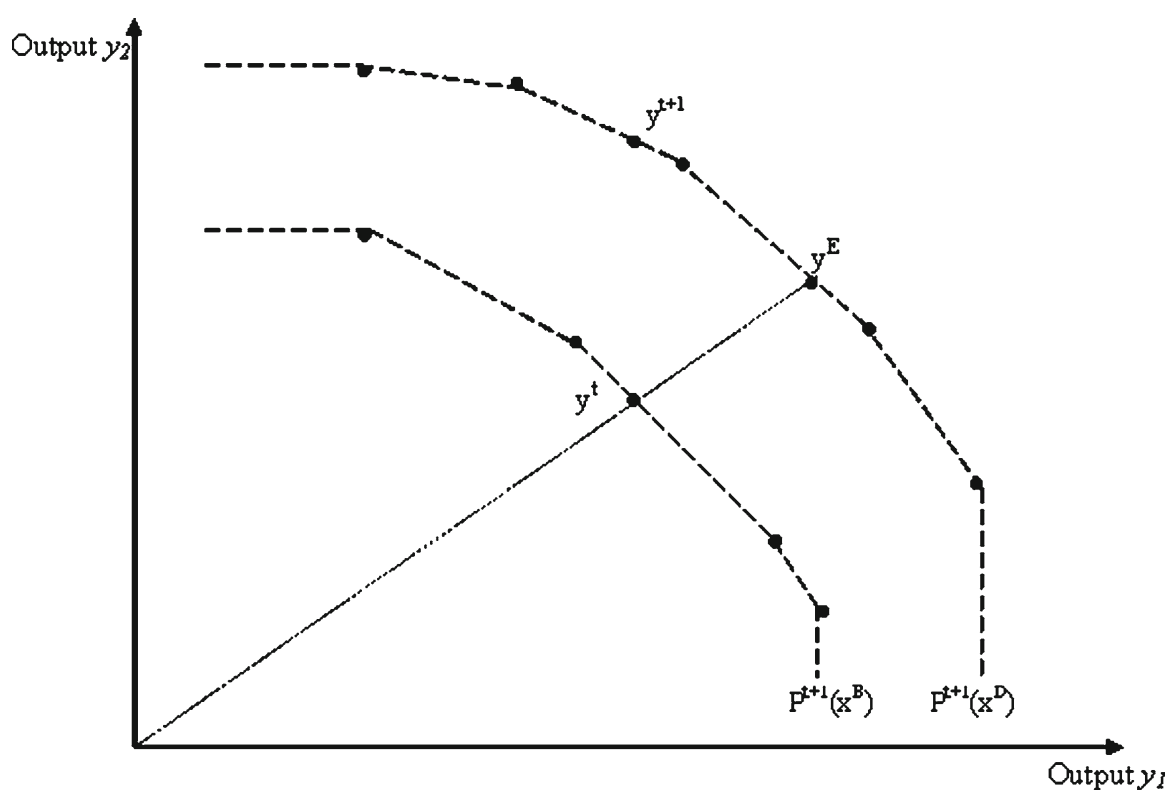

Fig. 2 Output efficient boundaries

The output scale effect is visualized in Fig. 2 with two outputs $y_{1}$ and $y_{2}$ on the axes. The output correspondence set $P^{t+1}\left(x^{B}\right)$ measures the maximum obtainable outputs which are producible by the best practice technology in $t+1$ and the input level $x^{B}$. Increasing the inputs to the level of $x^{D}$, but holding the output mix the same as at $y^{t}$, the output scale effect is measured as $y^{E}-y^{t}$.

From Fig. 1, for a given production of outputs in reference period $t+1$, we can infer the shift in input use from base period $t$ to reference period $t+1$. This is visualized by the difference between the efficient input level for producing $y^{t+1}$ (but holding the input mix similar as in the base period) and the efficient input level $x^{C}$ in $t+1$. The obtained difference $x^{D}-x^{C}$ is the resource mix effect. Similarly, in Fig. 2 the product mix effect is the shift in outputs from $y^{E}$ to $y^{t+1}$.

Together, the resource mix (first term in Eq. 4), the product mix (second term) and the scale effects (difference between the last two terms) constitute the activity effect:

$$
\begin{aligned}
& \left(y^{t+1}-y^{t}\right) p^{t}-\left(x^{C}-x^{B}\right) w^{t} \\
& \quad=\left(x^{D}-x^{C}\right) w^{t}-\left(y^{E}-y^{t+1}\right) p^{t}+\left(x^{B}-x^{D}\right) w^{t}-\left(y^{t}-y^{E}\right) p^{t} .
\end{aligned}
$$

The unobserved inputs $x^{D}$ and outputs $y^{E}$ can be obtained from, respectively, inefficiency relative to the efficient input requirement frontier $\theta^{t+1}\left(x^{t}, y^{t+1}\right) * x^{t}$ and the inefficiency relative to the efficient output correspondence frontier $\lambda^{t+1}\left(x^{D}, y^{t}\right) * y^{t}$. In the next section, we therefore demonstrate how to estimate these inefficiencies without any a priori assumptions with regard to the production technology, and while allowing for noise and heterogeneity in the data. 


\section{Non-parametrically estimating efficient quantities}

To decompose profit change into technical change, efficiency change, product mix, resource mix, scale and price effects, unobserved quantities $x^{A}, x^{B}, x^{C}, x^{D}$ and $y^{E}$ have to be deduced. These can be obtained by linking the inefficiency estimates to the observed quantities $\left(x^{t}, y^{t}\right)$ and $\left(x^{t+1}, y^{t+1}\right)$. To estimate the inefficiencies, GrifellTatjé and Lovell $(1999,2008)$ suggest a sequential DEA model to recover the unobserved quantities from observed input-output combinations. We further develop their approach by employing a non-parametric DEA model (see Sect. 4.1) which allows for uncertainty in the data (Sect. 4.2) and which takes into account heterogeneity in the sample (Sect. 4.3). The latter is particularly important because it restricts the DEA model so that a particular observation's efficiency score is based on a comparison with other similar observations, and as such, should provide more appropriate efficiency scores, and hence more meaningful profit decompositions. The model is constructed step by step in the following subsections.

\subsection{DEA in panel data}

To evaluate the efficiency of entities, several techniques have been proposed. In this section, we concentrate on a DEA (Charnes et al. 1978) model which estimates inefficiency relative to a best practice frontier (for an extensive description of DEA, we refer to Fried et al. 2008). Although DEA does not assume any a priori specification of the production function, it relies on two presumptions which are easily defendable in the application under study. In particular, it assumes free disposability of the inputs and outputs: $\forall\left(x^{t}, y^{t}\right) \in \Psi^{t}$, if $\widetilde{x}^{t} \geq x^{t}$ and $\widetilde{y^{t}} \leq y^{t}$ then $\left(\widetilde{x^{t}}, \widetilde{y^{t}}\right) \in \Psi^{t}$ [where $\Psi^{t}$ denotes the production technology set: $\Psi^{t}=\left\{\left(x^{t}, y^{t}\right) \mid x^{t} \in \mathbb{R}_{+}^{p}, y^{t} \in \mathbb{R}_{+}^{q},\left(x^{t}, y^{t}\right)\right.$ is feasible $\left.\}\right]$, or stated verbally: if a particular input-output combination $\left(x^{t}, y^{t}\right)$ is feasible, it should also be possible to produce $y^{t}$ with more inputs and to produce less outputs with a given input set $x^{t}$. In addition to the free disposability assumption, DEA assumes a convex shape for the frontier: if $\left(x_{1}^{t}, y_{1}^{t}\right),\left(x_{2}^{t}, y_{2}^{t}\right) \in \Psi^{t}$, then $\forall \alpha \in[0,1]:\left(x^{t}, y^{t}\right)=\alpha\left(x_{1}^{t}, y_{1}^{t}\right)+(1-\alpha)\left(x_{2}^{t}, y_{2}^{t}\right) \in \Psi^{t}$. As such, the corresponding best practice production set is defined as a convex hull of the undominated input-output combinations:

$$
\begin{aligned}
\Psi_{\mathrm{DEA}}^{t}= & \left\{\left(x^{t}, y^{t}\right) \in \mathbb{R}_{+}^{p+q} \mid x^{t} \geq \sum_{i=1}^{n} \gamma_{i} x_{i}^{t}, y^{t} \leq \sum_{i=1}^{n} \gamma_{i} y_{i}^{t}, \text { for }\left(\gamma_{1}, \ldots, \gamma_{n}\right),\right. \\
& \text { s.t. } \left.\sum_{i=1}^{n} \gamma_{i}=1, \gamma_{i} \geq 0, i=1, \ldots, n\right\} .
\end{aligned}
$$

The relative input-oriented inefficiencies, $\theta(x, y)$, which minimize inputs for a given output, and output-oriented inefficiencies, $\lambda(x, y)$, which maximize outputs for given inputs, are obtained by determining the appropriate distance to this best practice frontier (see Fried et al. 2008 for further details).

In order to adapt the DEA estimators to a panel data set, we use a Window Analysis technique (e.g., Fried et al. 2008). A window analysis operates in a panel sample by the principle of moving averages so that an observation is evaluated against all entities in 
its 'window' (i.e., the reference set is enlarged to include observations from different years). By using window analysis we allow for both technical progress and regress, which is not the case in the sequential DEA analysis of Grifell-Tatjé and Lovell (1999, 2008). In the current application, we assume a window size equal to 3 years and limit the scope of the window to the past. This corresponds to the evaluation of the reference period (i.e., $t$ or $t+1$ ) and the two proceeding years. ${ }^{2}$ As such, we can obtain the efficiency scores $\theta^{t}\left(x^{t}, y^{t}\right)$ and $\lambda^{t}\left(x^{t}, y^{t}\right)$ needed for the profit decomposition.

\subsection{Allowing for uncertainty in the data}

However, a major disadvantage of the traditional DEA model lies in its deterministic nature as it assumes that all observations $\left(x_{i}^{t}, y_{i}^{t}\right)$ belong to the production set of size $n$, i.e., $\operatorname{Prob}\left(\left(x_{i}^{t}, y_{i}^{t}\right) \in \Psi^{t}\right)=1$ for all $i=1, \ldots, n$. As such, atypical or outlying observations could bias the estimates if they dramatically influence the best practice frontier.

To reduce the influence of atypical observations, Cazals et al. (2002) suggests estimating efficiency relative to a partial best practice frontier constituted from $m<n$ observations, instead of estimating the efficiency relative to the full best practice frontier constituted from all $n$ observations. For the evaluated observation $\left(x^{t}, y^{t}\right)$ this so-called robust order- $m$ approach draws for the input or output-orientation a sample of size $m$ with replacement, respectively, among those $x_{i}^{t}$ so that $y^{t} \leq y_{i}^{t}$ or among those $y_{i}^{t}$ so that $x^{t} \geq x_{i}^{t}$. For the obtained sub-sample, the non-parametric model is then computed. After repeating the sampling and efficiency evaluation $B$ times, the robust efficiency scores $\theta^{t, m}\left(x^{t}, y^{t}\right)$ and $\lambda^{t, m}\left(x^{t}, y^{t}\right)$ are obtained by taking the arithmetic average of the $B$ inefficiencies. Given this approach, the partial frontier will shift inwards relatively to the full frontier (i.e., $\Psi^{t} \subset \Psi^{t, m}$ ) such that $\theta^{t, m} \geq \theta^{t}$ and $\lambda^{t, m} \leq \lambda^{t}$, (see Daraio and Simar 2007 for details on the practical implementation of this robust order- $m$ DEA approach).

As the evaluated observation does not constitute its reference set in every of the $B$ drawings, robust DEA estimation can potentially result in 'super-efficient' efficiency scores (i.e., $\theta^{t, m}>1$ or $\lambda^{t, m}<1$ ). However, as 'super-efficiency' is inconsistent with the profit decomposition framework, these super-efficient observations will result in biased profit decomposition estimates. We therefore adopt the common practice in the traditional DEA framework, and treat any super-efficient observation as efficient (i.e., we set any $\theta^{t, m}>1$ or $\lambda^{t, m}<1$ equal to 1$)$.

Following Daraio and Simar (2007), the size of the partial frontier $m$ and the number of resamplings $B$ is determined as the value for which the number of super-efficient observations decreases only marginally by further increasing $m$ or $B$ (i.e., the percentage of points outside $\Psi^{t}$ is practically constant). In our analysis, we determined $m=50$ and $B=300$.

Robust order- $m$ DEA estimates are attractive for several reasons. Firstly, they reduce the influence of atypical and outlying observations. In our particular application, we

\footnotetext{
2 To test the robustness of this assumption, we experimented with window sizes ranging from 2 to 6 years and found similar results.
} 
need to account for outlying observations as these could arise from (1) measurement errors, (2) the impact of mergers or (3) wrongly estimated values due to particular accounting rules. Indeed, as annual accounts are not particularly designed for economic analysis, the (industrial economics) literature argues that one should account for this by carefully constructing appropriate input variables (e.g., Taylor 1999; Salvary 2003). The influence of any such atypical observations is reduced by order- $m$ estimation. Secondly, by estimating efficiency relatively to a partial frontier $(m<n)$, the robust estimation technique reduces the sample size bias which could arise from the window analysis approach (for a simulation, see De Witte and Marques 2008). Indeed, Zhang and Bartels (1998) indicate that with standard DEA individual and average efficiency decreases as the number of observations in the sample increases. This issue is mostly neglected in DEA applications. Finally, the order- $m$ procedure can easily be extended to conditional efficiency measures which incorporate heterogeneity in the estimates, and we turn to this issue in the next subsection.

\subsection{Taking into account heterogeneity}

While the order- $m$ DEA approach allows for uncertainty, it still assumes that all observations are evaluated against the same frontier constructed from the overall best practices in the subsample of size $m$. However, this is a rather blunt approach as there might arise significant heterogeneity among observations. Some observations could operate in a favorable (unfavorable) environment which acts as a substitutive input (output) and, thus, increases (decreases) the efficiency scores. However, it is generally appropriate to control for differences in operating environment and therefore compare only comparable (defined as having comparable exogenous characteristics) entities. To take into account the operational environment non-parametrically, Cazals et al. (2002) and Daraio and Simar (2005); Daraio and Simar (2007) propose an extension of the order- $m$ DEA approach that effectively compares like with likes. This is implemented by conditioning on the environmental variable $z_{i}^{t}$.

The robust and conditional efficiencies are obtained by adapting the previously outlined order- $m$ sampling procedure as follows. For each of the $B$ draws, the reference sample of size $m$ is drawn with replacement and with a probability $K\left(\left(z^{t}-\right.\right.$ $\left.\left.z_{i}^{t}\right) / h\right) / \sum_{j=1}^{n} K\left(\left(z^{t}-z_{i}^{t}\right) / h\right)$ among those $x_{i}^{t}$ such that $y_{i}^{t} \geq y^{t}$ for the input-orientation, or among those $y_{i}^{t}$ such that $x_{i}^{t} \leq x^{t}$ for the output-orientation; where $K(\cdot)$ denotes a Kernel function. Relative to these environment-adjusted reference samples, we then proceed as discussed in the preceding sub-sections: we first estimate the input or output-oriented efficiency model relatively to the reference sample; then re-do this $B$ times; and finally average the $B$ efficiency evaluations to obtain the robust conditional efficiency estimate $\theta^{t, m}\left(x^{t}, y^{t} \mid z^{t}\right)$ and $\lambda^{t, m}\left(x^{t}, y^{t} \mid z^{t}\right)$.

In the remainder of this article, we will focus on these robust conditional DEA estimates constructed in a window analysis. To compute by this model the unobserved quantities $x^{A}=\theta^{t, m}\left(x^{t}, y^{t} \mid z^{t}\right) * x^{t} ; x^{B}=\theta^{t+1, m}\left(x^{t}, y^{t} \mid z^{t}\right) * x^{t}$; $x^{C}=\theta^{t+1, m}\left(x^{t+1}, y^{t+1} \mid z^{t+1}\right) * x^{t+1} ; x^{D}=\theta^{t+1, m}\left(x^{t}, y^{t+1} \mid z^{t+1}\right) * x^{t}$ and $y^{E}=$ $\lambda^{t+1, m}\left(x^{D}, y^{t} \mid z^{t}\right) * y^{t}$, both the evaluated observation and the period of its reference observations have to be adapted accordingly in the outlined model. In the next 
section, we apply the resulting robust conditional efficiency estimates to compute the unobserved quantities in a profit decomposition of the Dutch drinking water utilities.

\section{Profits and productivity in the Dutch drinking water sector}

As indicated in Sect. 2, the introduction of sunshine regulation was an important landmark in the reform of the Dutch drinking water sector. In this section, we empirically explore its effect on utility performance by decomposing profit change into its drivers. We first describe the data before continuing with the empirical results.

The panel data set consists of water only companies in the period 1992-2006. All data are obtained from annual accounts, sector publications by Vewin and the periodic benchmark reports. To control for the impact of inflation, all monetary values are expressed in thousands of 1995 euros (using the CPI of the Dutch Office for Statistics, Centraal Bureau voor Statistiek). Our sample consists of a set of 19 water utilities in 1992, and all these firms or the successor firms that resulted from mergers between them in subsequent years. Therefore, while the number of firms declines to only 10 in 2006, the geographic coverage of the firms represented in the sample remains the same, although we do note that in 2003 a merger occurred between a firm in our sample and an extremely small firm not previously represented in the sample. Therefore, with only this minor exception, comparisons based on aggregate changes in our sample across time provide a consistent estimate of trends in the sector. Moreover, to investigate the underlying dynamics in the sector as well as possible, we did not exclude mergers from the sample (as, Grifell-Tatjé and Lovell 1999 does). Instead, to allow for profit change decomposition after mergers, we construct a 'merged' firm for year $t-1$ as the sum of the data for the predecessor firms that are subsequently combined in year $t$. By doing so, we can estimate profit changes between year $t-1$ (i.e., the merged utility constructed from its predecessor) and $t$ (when data from the newly merged firm is available). ${ }^{3}$

In our analysis we follow Eq. 1 to construct a measure of economic profits at time $t\left(\pi^{t}\right)$ as turnover $\left(R^{t}=\sum_{m=1}^{q} p_{m}^{t} y_{m}^{t}\right)$ less total economic costs $\left(C^{t}=\sum_{l=1}^{p} w_{l}^{t} x_{l}^{t}\right)$. Calculation of economic profits and hence profit change therefore requires appropriate data on observed output $\left(y_{m}^{t}\right)$ and input $\left(x_{l}^{t}\right)$ quantities as well as output $\left(p_{m}^{t}\right)$ and input prices $\left(w_{l}^{t}\right)$. While profit change can be decomposed into the quantity and price effects detailed in Eq. 2 with this information alone, the further decomposition detailed in Sect. 3 requires the revelation of unobserved output and input quantities with the non-parametric model detailed in Sect. 4.

\footnotetext{
3 By definition, with this assumption the overall estimated individual profit change for a merged firm and its predecessor companies is equivalent to the change observed between the profit of the successor firm and the total profit of the predecessor firms. Moreover, as only 8 mergers appear in the sample of 228 individual profit change decompositions underlying our aggregate results, we must make this assumption for only a limited number of observations. However, while total profit change is not affected, we note that there does exist a theoretical potential for bias in the decomposition of profit change for the 8 individual profit change decompositions spanning a merger event, due to possible misspecification of the relevant frontier for the merged firm. However, sensitivity analysis shows that relative to firm size, the individual profit decompositions for the 8 potentially biased merger observations are in line with the individual profit decompositions for the 220 unbiased companies.
} 
In our specification of total economic costs, we allow for capital $\left(x_{K}^{t}\right)$, labor $\left(x_{L}^{t}\right)$ and 'other' $\left(x_{O}^{t}\right)$ inputs, and the corresponding input prices $w_{K}^{t}, w_{L}^{t}$, and $w_{O}^{t}$. Labor costs are observed in the annual accounts, as are the number of full time equivalent employees, which we employ as our proxy for $x_{L}^{t} \cdot w_{L}^{t}$ is then calculated as labor costs divided by $x_{L}^{t}$. Other costs is calculated by subtracting labor costs from total operating expenditures, as observed in the annual accounts. As it is the best available price proxy for other costs in the Dutch water industry, we proxy $w_{O}^{t}$ with the (material) construction price index as annually published by the Dutch Office for Statistics. The proxy for other input usage $\left(x_{O}^{t}\right)$ is then computed by dividing other costs by $w_{O}^{t} \cdot{ }^{4}$ The economic (opportunity) cost of capital is estimated as the sum of depreciation (from the annual accounts) and an estimated opportunity cost of capital. The latter is computed by multiplying the book value of assets by the opportunity cost of capital, which we estimate as the yield on the risk free 10 year Dutch government bond plus a risk premium of $4 \% .{ }^{5}$ Our estimate of $w_{K}^{t}$ is then calculated by dividing the estimated economic cost of capital by mains length, which serves as our physical proxy for $x_{K}^{t}$.

Total revenues are drawn from the companies' annual accounts, but we have limited the number of output variables to two in order to avoid difficulties with the degrees of freedom in the non-parametric model. We opted for two consensual output variables related to production, i.e., water production for domestic $\left(y_{D}^{t}\right)$ and non-domestic $\left(y_{N}^{t}\right)$ customers. However, robustness tests with outputs based on different partitions of total water production or the number of water connections (both aggregated and divided into domestic and non-domestic customers) delivered similar results. Output prices are deduced from Vewin's annual Water Supply Statistics report and are equivalent to the average price paid per cubic meter of water by domestic $\left(p_{D}^{t}\right)$ and non-domestic customers $\left(p_{N}^{t}\right)$. Aggregate statistics for our sample are provided in Table 1.

To account for heterogeneity in the data, we estimate the robust and conditional efficiency measures detailed in Sect. 4, using population density (computed by number of connections per kilometer of network length) as our environmental conditioning variable $\left(z_{i}^{t}\right)$. Population density is widely considered to be an important determinant of water utility input requirements, because the relatively smaller input requirements associated with distributing water in more densely populated areas result in economies of network density (see Filippini et al. 2008). It is therefore appropriate to condition efficiency scores on population density, as otherwise the relatively high input requirements of utilities operating with low population density would be inappropriately modelled as inefficiency. Sensitivity analysis of our profit decomposition without accounting for the exogenous environment (i.e., the regular deterministic DEA model or the order- $m$ model) confirm this potential bias. Moreover, we would also argue that such unconditional DEA models would result in potentially biased estimates of the

\footnotetext{
4 While it would be desirable to further decompose other costs into components such as energy costs, chemicals, and contracted out services, the necessary data to allow this are not available.

5 A 4\% risk premium follows the literature (Brigham et al. 1985) and expert views in the Dutch water sector. As total economic costs are influenced by the risk premium, a $4 \%$ risk premium corresponds to a favorable assumption for drinking water utilities. This is because it gives them the benefit of the doubt, particularly at the end of the sample period when economic profits in the industry are found to be relatively high. Thus, alternative models with lower assumed risk premiums result in lower total economic costs and hence even greater economic profits than those reported here.
} 


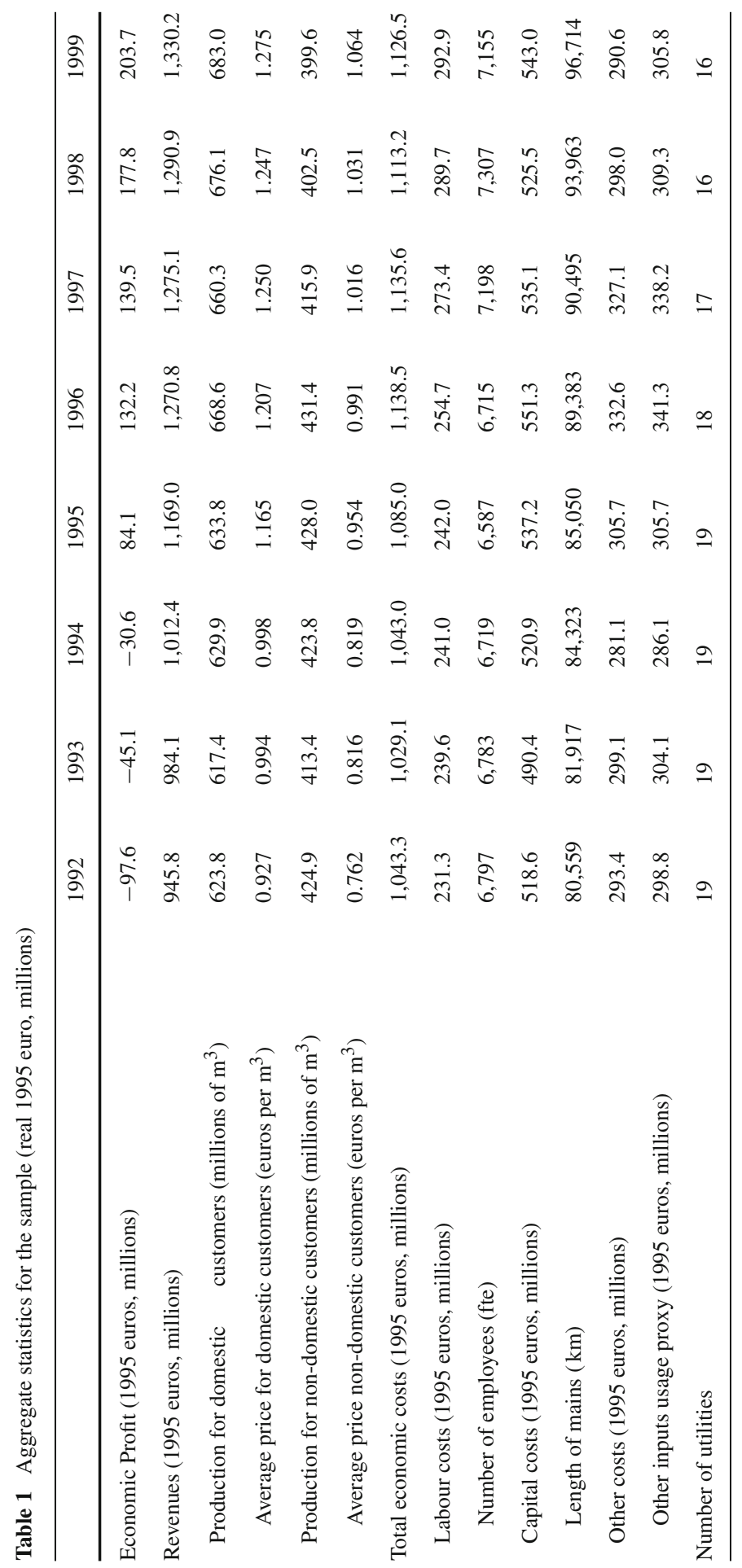




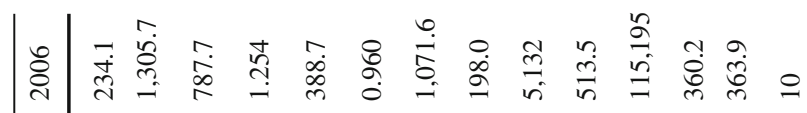

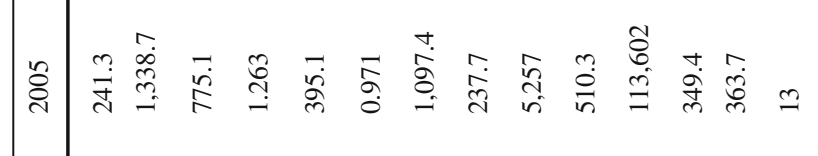

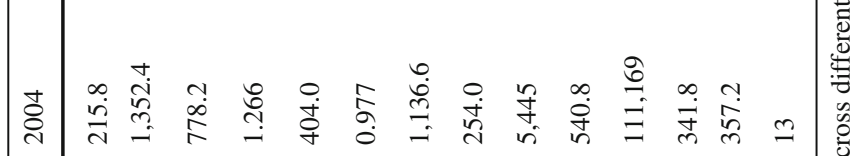

饣)

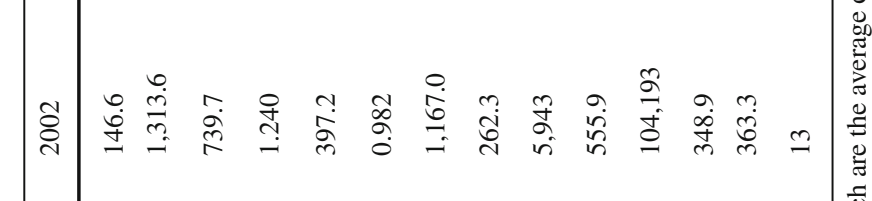

-

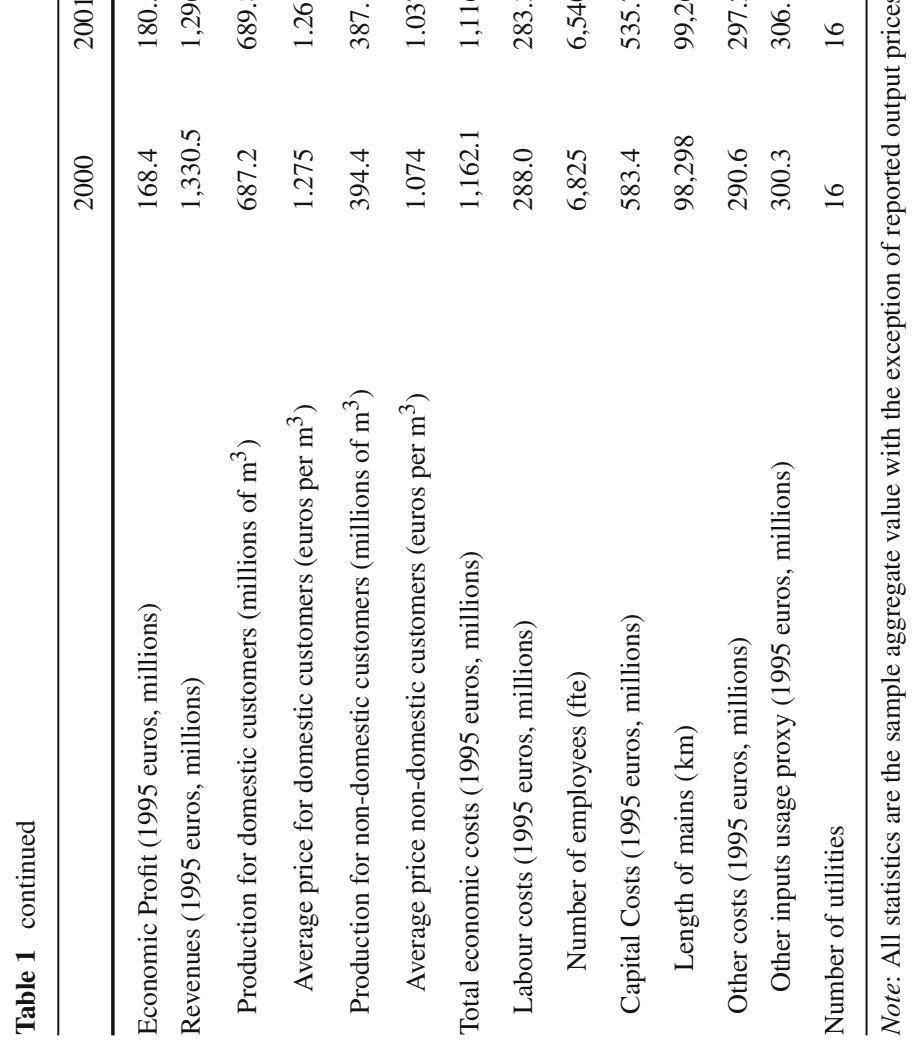


Table 2 Cumulative effect (real 1995 euro, millions)

\begin{tabular}{clllll}
\hline & $1992-1997$ & $1997-2006$ & $1997-2000$ & $2000-2003$ & $2003-2006$ \\
\hline Profit change & 237.1 & 94.6 & 28.9 & 27.0 & 38.7 \\
Quantity effect & -76.6 & 40.4 & 15.5 & 40.5 & -15.7 \\
Productivity & -100.9 & 227.9 & 78.2 & 65.9 & 83.7 \\
Technical change & 12.3 & 214.0 & 22.7 & 113.9 & 77.3 \\
Efficiency change & -113.1 & 13.9 & 55.5 & -48.0 & 6.4 \\
Activity effect & 24.3 & -187.5 & -62.7 & -25.4 & -99.4 \\
Product mix & 22.0 & 17.6 & -31.3 & 52.4 & -3.5 \\
Resource mix & 0.7 & -254.3 & -55.8 & -65.4 & -133.1 \\
Scale effect & 1.5 & 49.2 & 24.4 & -12.4 & 37.2 \\
Price effect & 313.7 & 54.2 & 13.4 & -13.6 & 54.4 \\
Input price effect & 29.5 & 158.1 & -31.1 & 86.5 & 102.7 \\
Capital & 49.1 & 183.2 & -1.5 & 96.7 & 88.0 \\
Labour & -25.2 & -17.4 & -29.6 & -17.0 & 29.2 \\
Other inputs & 5.6 & -7.7 & 0.01 & 6.8 & -14.5 \\
Output price effect & 284.1 & -103.9 & 44.5 & -100.1 & -48.4 \\
Domestic consumers & 185.2 & -43.1 & 25.3 & -39.2 & -29.1 \\
Non-domestic consumers & 99.0 & -60.9 & 19.2 & -60.9 & -19.2 \\
\hline
\end{tabular}

activity effect, which relies on the estimation of efficient input and output quantities that are, in practice, heavily influenced by environmental factors such as population density. ${ }^{6}$

Given space limitations, Table 2 reports, in aggregate for our entire sample, the cumulative change in profits and its decomposition, for the 1992-1997 period before sunshine regulation was introduced and the entire sunshine regulation period. Moreover, given the regulatory periods discussed in Sect. 2, Table 2 also reports cumulative profit change and its decomposition for the 1997-2000, 2000-2003, and 2003-2006 periods. ${ }^{7}$

\subsection{The pre-sunshine period: $1992-1997$}

In the period before the introduction of sunshine regulation our estimates suggest a dramatic change in economic profitability. Thus, between 1992 and 1997 economic losses of -97.6 million euros were eliminated and replaced with significant economic profits amounting to 139.5 million euros. As Table 2 clearly illustrates, $132 \%$ of this 237.1 million euro increase in profitability was realized because of changes in out-

\footnotetext{
6 Stated differently, the activity effect decompositions are particularly worrisome if one fails to allow for the operational environment: by comparing 'apples with oranges' in a non-conditional efficiency framework the decomposition may erroneously assign heterogeneity to the scale, product mix, or output mix effect, rather than properly allowing for legitimate differences in input requirements associated with increased or reduced population density.

7 Estimates of year-by-year changes are available from the authors upon request.
} 
put and input prices that benefited the companies. More specifically, output prices increased substantially for both domestic and non-domestic consumers, contributing 284 .1 million euros to increased profits. In aggregate, reduced input prices also contributed 29.5 million euros to profit change, although substantial contributions to profitability from reductions in the price of capital and other inputs, were offset by increases in the price of labor.

In contrast to the overall positive impact of the price effect on profits, the cumulative impact of the quantity effect between 1992 and 1997 resulted in a 76.6 million euro reduction in profits. This negative effect can be entirely attributed to the negative productivity effect which decreased profits by 100.9 million euros. Moreover, the entire negative productivity effect can be attributed to reduced efficiency $(-113.1$ million euros), given the small positive contribution attributable to technical change (12.3 million euros). The activity effect is also notable during this period, as it is not only small, but almost exclusively attributed to changes in product mix as a small decline of non-domestic consumption, coupled with growth in domestic consumption led to relatively more production for domestic consumers, thereby contributing to profitability. However, on balance there is little to no evidence that structural changes, as captured by changes in the mix of inputs, outputs or scale, were influencing aggregate profitability substantially before 1997 .

Thus, while profits clearly increased because of price increases to consumers, there is substantial contradictory evidence to suggest that economic performance, as measured by the quantity effect, and more specifically efficiency, actually declined during the period before sunshine regulation was implemented. It seems that the absence of any effective mechanism to incentivize improved performance resulted in dramatically reduced performance as managers did not face any effective pressure to reduce costs. This result mirrors the findings of Saal and Parker $(2000,2001)$ who found that privatisation did not improve performance in the English and Welsh water sector until a more effective incentive regime was implemented in 1995. It also confirms previous research on the Dutch water sector (De Witte and Dijkgraaf 2008; Dijkgraaf et al. 2007a).

\subsection{The post sunshine period: 1997-2006}

Our results suggest that the introduction of the sunshine regulatory model in 1997 substantially altered aggregate profit performance and its determinants. Focusing first on aggregate profit change, we see that for the entire 1997-2006 period, profits increased by only 94.6 million euros, which was the result of roughly equal aggregate profit increases for each of the 1997-2000, 2000-2003, and 2003-2006 periods. Relative to the pre sunshine period, profit growth was therefore relatively slow. However, while the small positive price effect of 54.2 million euros for this period is also relatively small, delving deeper reveals that lower real output prices reduced profits by 103.9 million euros and lower input prices contributed a positive effect of 158.1 million euros. Thus, in sharp contrast to pre 1997 experience, between 1997 and 2006 positive profit growth was achieved despite considerable reductions in output prices, and was aided by reductions in real input prices. However, it is noteworthy that a disproportionate share of the benefits from output price reductions accrued to non-domestic consumers. 
The large positive 227.9 million euro contribution to profits attributable to productivity change between 1997 and 2006 similarly contrasts to the negative productivity effect experienced before the introduction of sunshine regulation, thereby suggesting a considerable shift in the productive performance of the water utilities. Moreover, this change was sustained in each of the 1997-2000, 2000-2003, and 2003-2006 periods. However, $93 \%$ of the contribution of productivity growth is attributable to technical change (214.0 million euros), which was similarly sustained over the entire period. In contrast, while the considerable efficiency loss of the pre 1997 period was replaced by positive efficiency change contributing 13.9 million to profits between 1997 and 2006, its contribution to overall productivity growth and profitability was both small and erratic, as evidenced by the -48.0 million euro contribution of efficiency change to profits between 2000 and 2003. On balance however, these results suggest that after 1997 Dutch drinking water utilities operated in an environment in which profit change was primarily driven by productivity improvements, and consumers appear to have eventually received a substantial portion of the resulting cost reductions in reduced output prices.

However, it is worthwhile to note that while a clear shift in underlying productivity performance is evident from the introduction of sunshine regulation in 1997, the pattern of the output price, quantity, and productivity effects suggest that consumer benefits, as well as underlying performance improvements, were most evident after 2000, and particularly in the 2000-2003 period. As benefits to consumers in reduced output prices are concentrated in the 2000-2003 and 2003-2006 periods, we would again note a parallel with the case of the English and Welsh water sector, where a similar pattern of performance improvements preceding consumer benefits is evident and accepted on the grounds that firms must retain the benefits of performance improvements for some period of time in order to provide appropriate incentives. The increasing focus in the Dutch media and in Dutch academic journals on excessive profits in the water industry during this period clearly suggests that the water utilities and/or politicians responded to public opinion with large output price declines. Nevertheless, while output price reductions led to a 148.5 million euro reduction in economic profits between 2000 and 2006, economic profits actually increased from 168.4 to 234.1 million euros over the same period, thereby suggesting that productivity incentives were not dampened by the onset of output price reductions.

We would finally note that as the potential establishment of an independent regulator was debated during the 2000-2003 period it is plausible that the industry increased its performance under sunshine regulation during this period precisely because it sought to avoid the implementation of a more robust incentive regulation system, and not because sunshine regulation itself enhanced performance. However, while this is plausible, periodic in earnest discussion of the possible establishment of an independent regulator, cannot explain the continuing shift to positive productivity change in every year after 1997 when sunshine regulation was introduced. Moreover, we would also argue, that if the mere threat of movement to an alternative regulatory system from the preferred sunshine regulatory model is sufficient to substantially improve company performance, this threat is always available to policy makers wishing to maintain the effectiveness of a sunshine regulation system. 
Nevertheless, our models do suggest some substantial negative evidence with regard to underlying company performance, as over 1997-2006 the activity effect resulted in a substantial negative profit change amounting to 187.5 million euros, thereby reducing the overall quantity effect to only 40.4 million euros. However, closer inspection of Table 2 reveals that in aggregate, this negative effect is driven by the resource mix effect (contributing -254.3 million euros to profits) which counteracted a relatively small positive scale effect (49.2 million euros) and the product mix effect (17.6 million euros), with the latter only being positive during 2000-2003. The scale effect result suggests that while on balance economic costs were reduced through increased scale (i.e., the many mergers), the magnitude of these benefits is quite small in comparison to productivity improvements. Nevertheless, these results are in line with Van Damme and Mulder (2006), who observe that companies exploit their larger scale to increase profits. The product mix effect contributes positively to profits, suggesting that changes in output mix have contributed to increased profitability. Indeed, from the underlying data we observe that, production for large customers decreased over time, production for small customers increased significantly, and price reductions for large customers have far outweighed those for small customers since 2000.

We believe the substantial negative resource mix effect captures the impact of efforts to increase security of supply, which have accompanied water mergers in the Netherlands. Indeed, when two utilities are merged, subsequent dramatic increases in the length of mains (i.e., capital) are generally observed, and justified as necessary to increase water supply security by allowing transfer of water resources between previously physically separated networks. This has resulted in a $27.3 \%$ increase in mains length between 1997 and 2006, while total water production has only increased by $9.3 \%$ (as calculated from the sample aggregate data in Table 1). ${ }^{8}$ Although, increasing network length aims to increase the security of supply, it also has a direct negative impact on profits, which has been captured by the resource mix effect. In other words, the negative resource mix effect suggests that the net impact of the industry's move to a less labor intensive but more capital and other input intensive structure, has resulted in increased costs of production. This is not contradictory to the finding of positive technical change, which implies that the industry is using a more productive technology, and to the positive efficiency effect, which implies that inefficient firms have eliminated technical efficiency. Stated differently, while the industry has seen substantial productivity improvements because it has reduced its input usage relative to outputs, its restructuring efforts have also, unfortunately, resulted in higher than economically efficient costs because of an increasing misalignment between input prices and the marginal rate of technical substitution between inputs. While increased security of supply may or may not justify the resulting increase in economic costs, it is simply beyond the scope of this study to determine the benefit of this unpriced and difficult to measure 'output'.

\footnotetext{
8 As this increase in water supply security cannot be measured and is therefore not included as an output in the model, this could potentially result in an overstatement of the negative resource mix effect. We would also note that as the expansion of the mains network is certainly designed to allow for future demand, the substantial capital investment programme pursued in the past 15 years could result in 'excessive' capital usage, which is nonetheless appropriate if we allow for potential future demand expansion.
} 
Overall, our profit decomposition results suggest that, subsequent to the introduction of light-handed sunshine regulation in 1997, the determinants of profit change in the Dutch drinking water sector have dramatically altered. Thus, despite some potential qualms created by the large negative resource mix effect and its suggestion that efforts to increase security of supply have substantially driven up economic costs in the industry, on balance, our results are consistent with the conclusion that the Dutch voluntary regulatory model has improved performance in the industry. In particular, our results suggest that Dutch water utilities have not only achieved substantial productivity improvements since 1997, but have also begun to pass these benefits back to consumers in reduced output prices. Nevertheless, given continuing substantial and increasing economic profits at the end of our sample period, our results also suggest that public concern with excessive profits may be justified, and that further output price reductions would bring revenues better in line with actual economic costs in the industry.

\section{Summary and conclusions}

In 1997, after pressure created by debate on the potential privatization of the regional water utilities, the publicly owned Dutch drinking water sector implemented a selfregulatory incentive scheme based on sunshine regulation (i.e., benchmarking with naming and shaming, but with no mandatory price regulation). In order to analyse the impact of this scheme on water industry performance, this paper has decomposed the sources of water utility profit change in the periods before and after sunshine regulation's introduction. To do so, it extends the decompositions of Grifell-Tatjé and Lovell $(1999,2008)$ by employing an advanced DEA model which allows for both atypical observations (resulting from the mergers and measurement errors) and heterogeneity in the data (Daraio and Simar 2007). The latter is particularly important as we need to control for differences in operating environment if we wish to properly measure efficient input requirements and thereby properly decompose the sources of profitability.

Analyzing the sources of profit change in the Dutch water sector suggests that the introduction of sunshine regulation appears to be associated with not only improved productivity in the industry, but also insuring that these productivity gains have begun to be passed to water consumers through reduced output prices. Thus, before the introduction of sunshine regulation in 1997, economic losses were transformed into economic profits by a substantial increase in output prices faced by consumers. Moreover, in this initial period there was also a substantial decline in the overall productivity of water utilities. In contrast, our results suggest that since 1997, the naming and shaming technique of sunshine regulation has resulted in substantial increases in productivity that are primarily attributable to technical change, and moderate reductions in real output prices, particularly after 2000, that returned a small proportion of these productivity gains to water consumers. Moreover, as economic profits, nonetheless increased between 2000 and 2006, our results suggest that these output price reductions did not accrue from political interference in favor of consumers, but were instead the result of passing past productivity improvements from producers to consumers. 
The model of sunshine regulation adopted in the Netherlands has therefore produced results that are broadly consistent with the goals of more formal incentive regimes in that the underlying productivity of the industry appears to have been improved, and a proportion of these productivity improvements are beginning to be transferred to consumers in reduced output prices.

Nevertheless, substantial and sustained economic profits in the Dutch water industry highlight a potential weakness of sunshine regulation in the long run. Stated differently, it would appear that the focus in the Dutch water industry has been primarily on improving the productive efficiency of the utilities, and improving security of supply, while a careful consideration suggests that relatively little attention has been given to the issue of improving allocative efficiency by more closely aligning water prices with the economic cost of water. Given that Dutch regional governments are the ultimate beneficiaries of water utility profitability, continued economic profits in the industry can also be seen as a tax whose incidence increases with water consumption, and which is transferred to consumers of government services. Moreover, while the continuation of the small declines in average real water prices for domestic and non-domestic consumers that have occurred since 2000 will apparently assuage public opinion, the absence of public discord does not eliminate the allocative inefficiencies caused by inappropriately high water prices.

On balance, the current implicit tax on water consumers may be an acceptable long term political solution in the Dutch context, and the sunshine regulatory model may therefore continue to be employed. Nevertheless, the Dutch experience still suggests that even under public ownership there may be inadequate mechanisms within the sunshine regulation model to guarantee a closer alignment between water prices and economic costs in the long run. This is because even with sustained public focus on excess profits since at least 2000 , the sunshine regime has only delivered a moderate reduction in output prices and the ultimate retention of substantial economic profits. Thus, while sunshine regulation appears to have provided sufficient incentives to improve productivity in the industry, and moderately rebalance tariffs in favor of consumers, it is likely that achieving closer alignment between water prices and economic costs, would require the establishment of a more formal regulatory framework, in which prices were set so as to better reflect economic costs (see, e.g., Maziotis et al. 2009).

In sum, while our results suggest that the sunshine regulatory framework has been an effective tool in the publicly owned Dutch water sector, the challenge of both maintaining long run incentives for productivity growth, and achieving a more appropriate alignment between economic costs and water prices is a substantial issue that will need to be addressed before it can be considered a fully viable alternative regulatory model. We therefore conclude by emphasizing that, sunshine regulation has achieved much in the Netherlands, but there remain three issues. Firstly, the regime in its current format could only be judged to be acceptable in situations where public ownership has been deemed to be a political necessity. Secondly, sunshine regulation requires sufficient public interest to provide the substantial oversight that forces managers to improve performance. Finally, policy makers should be willing to accept the potential misalignment of water prices and costs and the subsequent implicit tax on water consumers that this implies. 
Acknowledgements We would like to thank Per Agrell, Pablo Arocena, Jos Blank, Leticia Blazquez, Laurens Cherchye, Tim Coelli, Paul De Bijl, Elbert Dijkgraaf, Emili Grifell-Tatjé, Pierre Koning, Patrick Koot, Mathias Lorentz, Chris O’Donnell, Mika Kortelainen, Louis Orea, Sergio Perelman, Emmanuel Thanassoulis and seminar participants at Université Catholique de Louvain (UCL), Wissenschaftszentrum Berlin für Sozialforschung (WZB), the Tenth Workshop of the EURO Working Group on Decentralized Decision Making, Katholieke Universiteit Leuven (KUL), Centre for European Economic Research (ZEW) in Mannheim, Netherlands Bureau for Economic Policy Analysis (CPB), EWEPA XI conference and EARIE 09 for useful suggestions and comments. We are also grateful to two anonymous referees for constructive and insightful comments.

Open Access This article is distributed under the terms of the Creative Commons Attribution Noncommercial License which permits any noncommercial use, distribution, and reproduction in any medium, provided the original author(s) and source are credited.

\section{References}

Bauer, M. (2005). Administrative costs of reforming utilities. In D. Coen \& A. Héritier, Redefining regulatory regimes: Utilities in Europe. Cheltenham, UK: Edward Elgar.

Brigham, E., Shome, D., \& Vinson, S. (1985). The risk premium approach to measuring a utility's cost of equity. Financial Management, 14(1), 33-45.

Cazals, C., Florens, J., \& Simar, L. (2002). Nonparametric frontier estimation: A robust approach. Journal of Econometrics, 106(1), 1-25.

Charnes, A., Cooper, W. W., \& Rhodes, E. (1978). Measuring the efficiency of decision making units. European Journal of Operational Research, 2(6), 429-444.

Crew, M. A., \& Kleindorfer, P. R. (2002). Regulatory economics: Twenty years of progress? Journal of Regulatory Economics, 21(1), 5-22.

Daraio, C., \& Simar, L. (2005). Introducing environmental variables in nonparametric frontier models: A probabilistic approach. Journal of Productivity Analysis, 24(1), 93-121.

Daraio, C., \& Simar, L. (2007). Conditional nonparametric frontier models for convex and nonconvex technologies: A unifying approach. Journal of Productivity Analysis, 28, 13-32.

De Witte, K., \& Dijkgraaf, E. (2008). Mean and bold: On separating merger economies from structural efficiency gains in the drinking water sector. Tinbergen Discussion Paper 07/092, Erasmus University Rotterdam. Forthcoming in Journal of the Operational Research Society. (doi:10.1057/ jors.2008.129).

De Witte, K., \& Marques, R. (2008). Capturing the environment, a Metafrontier approach to the drinking water sector. Centre for Economic Studies Discussion Paper 08.04. International Transactions of Operational Research, 16, 257-271.

Dijkgraaf, E., de Jong, R., Mortel, E. G. v. d., Nentjes, A., Varkevisser, M., \& Wiersma, D. (1997). Mogelijkheden tot marktwerking in de Nederlandse Watersector (pp. 1-87). Den Haag: Ministerie van Economische Zaken.

Dijkgraaf, E., van der Geest, S. A., \& Varkevisser, M. (2007a). The efficiency gains of benchmarking Dutch water companies. Working Paper Erasmus University Rotterdam.

Dijkgraaf, E., van der Geest, S. A., \& Varkevisser, M. (2007b). Winstregulering als waarborg voor redelijke tarieven. Working Paper Erasmus University Rotterdam.

Filippini, M., Hrovatin, N., \& Zoric, J. (2008). Cost efficiency of Slovenian water distribution utilities: An application of stochastic frontier methods. Journal of Productivity Analysis, 29, 169-182.

Fried, H., Lovell, C. A. K., \& Schmidt, S. (2008). The Measurement of productive efficiency and productivity growth (638 pp). New York: Oxford University Press.

Grifell-Tatjé, E., \& Lovell, C. A. K. (1999). Profits and productivity. Management Science, 45(9), 11771193.

Grifell-Tatjé, E., \& Lovell, C. A. K. (2008). Productivity at the post: Its drivers and its distributions. Journal of Regulatory Economics, 33, 133-158.

Kuks, S. M. (2006). The Privatisation debate on water services in the placeNetherlands: Public performance of the water sector and the implications of market forces. Water Policy, 8, 147-169. 
Maziotis, A., Saal, D., \& Thanassoulis, E. (2009). Regulatory price performance, excess cost indexes and profitability: How effective is price cap regulation in the water industry? Aston University Working Paper RP 0920, 42 pp.

Parker, D. (1999). Regulation of privatized public utilities in the place UK: Performance and governance. International Journal of Public Sector Management, 12(3), 213-235.

Saal, D., \& Parker, D. (2000). The impact of privatization and regulation on the water and sewerage industry in England and Wales: A translog cost function model. Managerial and Decision Economics, 21(6), 253-268.

Saal, D., \& Parker, D. (2001). Productivity and price performance in the privatized water and sewerage companies of England and Wales. Journal of Regulatory Economics, 20(1), 61-90.

Salvary, C. (2003). Financial accounting information and the relevance/irrelevance issue. Global Business and Economics Review, 5(2), 140-175.

Spiller, P., \& Tommasi, M. (2004). The institutions of regulation. An application to public utilities. In C. Ménard \& M. Shirley, Handbook of new institutional economics. Boston/Dordrecht: Kluwer.

Taylor, C. (1999). The cash recovery method of calculating profitability: An application to pharmaceutical firms. Review of Industrial Organization, 14, 135-146.

Ugaz, C., \& Price, C. W. (2003). Utility privatization and regulation: A fair deal for consumers? (320 pp). Cheltenham, UK: Edward Elgar.

Van Damme, E. E. C., \& Mulder, K. J. (2006). Transparant en eerlijk geprijsd water. Economisch Statistische Berichten, 4482, 134-136.

Van Dijk, P., Schouten, M., Swami, K., \& Kooij, M. (2007). Country report on the Netherlands. In M. Finger, J. Allouche, \& P. Luis-Manso (Eds.), Water and liberalisation, European Water Scenarios. London: IWA Publishing.

Waterspiegel. (2001). Benchmark special. Opinion publication of Vewin. Association of Dutch Water Companies, 4(4), 1-21

Waterspiegel. (2001-2007). Opinion publication of Vewin. Association of Dutch Water Companies. Accessed March 10, 2008, from http://www.vewin.nl.

Waterspiegel. (2003). Huidig toezicht op waterbedrijven functioneert goed. Opinion publication of Vewin. Association of Dutch Water Companies, 6(6), 1-32.

Zhang, Y., \& Bartels, R. (1998). The effect of sample size on the mean efficiency in DEA with an application to electricity distribution in Australia, Sweden and New Zealand. Journal of Productivity Analysis, 9(3), 187-204. 